\title{
Palmitoylethanolamide for Sleep Disturbance. A Double-blind, Randomised, Placebo-controlled Interventional Study
}

\section{Amanda Rao ( $\square$ Amanda@rdcglobal.com )}

RDC Clinical

Phillippa Ebelt

RDC Clinical

Alistair Mallard

The University of Queensland

David Briskey

University of Queensland - Saint Lucia Campus: The University of Queensland https://orcid.org/00000001-9867-6700

\section{Research}

Keywords: Palmitoylethanolamide, Levagen, Sleep, Sleep onset

Posted Date: April 8th, 2021

DOl: https://doi.org/10.21203/rs.3.rs-376418/v1

License: (c) (i) This work is licensed under a Creative Commons Attribution 4.0 International License. Read Full License 


\section{Abstract}

Background: Sleep is essential for wellbeing, yet sleep disturbance is a common problem linked to a wide range of health conditions. Palmitoylethanolamide (PEA) is an endogenous fatty acid amide proposed to promote better sleep via potential interaction with the endocannabinoid system.

Methods: This double-blind, randomized study on 103 adults compared the efficacy and tolerability of 8 weeks of daily supplemented PEA formulation (350 mg Levagen $+{ }^{T M}$ ) to a placebo. Sleep quality and quantity were measured using wrist actigraphy, a sleep diary and questionnaires.

Results: At week 8, PEA supplementation reduced sleep onset latency, time to feel completely awake and improved cognition on waking. After 8 weeks, both groups improved their sleep quality and quantity scores similarly. There was no difference between groups at baseline or week 8 for sleep quantity or quality as measured from actigraphy or sleep diaries.

Conclusion: These findings support PEA as a potential sleeping aid capable of reducing sleep onset time and improving cognition on waking.

Trial registration: Australian New Zealand Clinical Trials Registry ACTRN12618001339246. Registered $9^{\text {th }}$ August 2018, http://www.anzctr.org.au/Trial/Registration/TrialReview.aspx?id=375493\&isReview=true

\section{Introduction}

Sleep is essential for mental and physical wellbeing (Chattu et al. 2018; Medic et al. 2017). Having a properly functioning sleep-wake cycle promotes survival (Worley 2018), adequate energy levels and normal motor and cognitive functioning (Walker et al. 2003; Kesner et al. 2020). Impaired sleep has been linked to a number of health consequences (Medic et al. 2017) such as: negative social functioning, accidents, cardiovascular disease, chronic pain, neurodegenerative disorders, depression, obesity, cancer and all-cause mortality (Chattu et al. 2018; Medic et al. 2017; Irwin et al. 2015; Krueger et al. 2008; Mullington et al 2010). An underlying pathogenesis to these health conditions is inflammation. Poor sleep quality has been shown to increase inflammatory mediators, potentially inducing the adverse physical and cognitive symptoms of sleep loss (Irwin et al. 2015, 2016; Krueger et al. 2008; Mullington et al. 2010). Poor sleep quality may also increase inflammation through increased sympathoadrenal activity, decreased glucose tolerance and neuroendocrine changes (Irwin et al. 2015; Krueger et al. 2008; Mullington et al. 2010)

The endogenous cannabinoid (endocannabinoid) system regulates numerous circadian processes including food intake, peripheral metabolism, and body temperature via the suprachiasmatic nucleus (Vaughn et al. 2010; Ho et al. 2008; Prospero-Garcia et al. 2016; Murillo-Rodriguez et al. 2011) and is involved in the sleep/wake cycle, (Kesner et al. 2020; Murillo-Rodriguez et al. 2011). The endocannabinoid system consists of lipid mediators that act upon specific receptors, including the nervous system (Kesner et al. 2020; Prospero-Garcia et al. 2016; Murillo-Rodriguez et al. 2011) It can also influence temperature 
regulation, fat storage, mood and behaviour regulation, sensory perception, motor activity, nervous system modulation, and endocrine and gastrointestinal (GI) function (Vaughn et al, 2010) - all previously shown to have an effect on sleep (Vaughn et al, 2010). Endocannabinoid signalling follows a circadian rhythm (Vaughn et al. 2010; Murillo-Rodriguez et al. 2011), such that sleep deprivation could lead to disruption to this cycle (Vaughn et al, 2010). Developing treatment strategies that target the endocannabinoid system could be a potential way to manage sleep disorders and disturbances.

Palmitoylethanolamide (PEA), an endogenous fatty acid amide, works synergistically with the endocannabinoid, anandamide (AEA) (Ho et al. 2008). AEA concentrations are low at sleep onset, increase during sleep and high at wakening (Vaughn et al. 2010; Ho et al. 2008). It is proposed that increased AEA signalling could facilitate deep non-rapid eye movement (NREM) sleep through inducing adenosine release (Prospero-Garcia et al. 2016). However, disturbed sleep is possibly related to impaired AEA signalling (Vaughn et al. 2010). Therefore, an exogenous dose of PEA could possibly restore dysregulated AEA signalling and facilitate better sleep. PEA is also proposed to have an effect on sleep due to its ability to act through transient receptor potential cation channel subfamily V member 1 (TrpV1). Activation of TRPV1 via increased AEA initiates vasorelaxation through a release of vasodilators (Vaughn et al. 2010; Zygmunt et al. 1999) and may facilitate sleep (Vaughn et al. 2010; Ho et al. 2008; Ambrosino et al. 2013; Franco-Cereceda et al. 1989).

Additionally, PEA's pain-alleviating and anti-inflammatory properties (Canteri et al. 2010; Evangelista et al. 2018; Chirchiglia et al. 2018; Conigliaro et al. 2011; Dalla Volta et al. 2016; Keppel Hesselink et al, 2012; Marini et al. 2012) could reduce pain and inflammation reported to impair sleep (Evangelista et al. 2018). A study by Evangelista et al found that $600 \mathrm{mg}$ of PEA administered to patients awaiting carpal tunnel syndrome surgery significantly improved patient's overall sleep quality, including an increase in continuous sleep time and a reduction of sleep latency (Evangelista et al. 2018). It was reported that this was due to its mitigation of pain symptoms in the treatment group encountering neuropathic pain, which contributed to their poor sleep quality (Evangelista et al. 2018). Such findings point to PEA as a potential option for sleep disorders.

A limitation to PEA's therapeutic efficacy is its traditionally poor bioavailability (Gabrielsson et al. 2016). Levagen $+\circledast$ is a clinically studied PEA formulation utilizing cold-water dispersible (CWD) technology (LipiSperse) that significantly increases plasma PEA concentrations by approximately 2 -fold (Briskey et al. 2020). Therefore, the aim of this study is to evaluate the efficacy of Levagen+® (PEA) supplementation on sleep quality and quantity in healthy adults with sleep pattern disturbance. It is hypothesised that PEA supplementation one hour prior to sleep onset will improve sleep quality, quantity and onset time.

\section{Materials And Methods}

This study was approved by the Bellberry Ltd Human research and ethics committee (approval number HREC2018-08-668-A-1) and carried out in accordance with current International Conference on 
Harmonization Guideline for Good Clinical Practice and registered on the Australian New Zealand Clinical Trials Registry (ACTRN12618001339246). Potential participants were recruited through databases and mainstream media from Brisbane, Australia and surrounding areas.

\section{Participants}

One hundred and twenty-five healthy males and females over 18 years of age with a disturbed sleeping pattern (> 5 on the PSQI) were recruited. Potential participants were screened for inclusion and exclusion criteria prior to providing written consent for enrolment. Inclusion criteria included: males and females (females of child-bearing potential being on a prescribed form of birth control), agree not to change current diet or exercise or use other supplements for sleep disturbances for the study period. Exclusion criteria included: any unstable or serious illness (e.g. kidney, liver, diabetes), malignancy or treatment for malignancy within the previous two years, clinically significant inflammation connective tissue disease or arthritis, suffered from any mood disorders such as depression and bipolar disorder, any neurological disorders such as multiple sclerosis, receiving or prescribed over the counter sleep medication or aid during the trial, diagnosed sleep apnea, diagnosed or consistent gastrointestinal issues that disrupt sleep, active smokers or those taking nicotine, prescribed drug or illegal substances, chronic past and/or present alcohol use (> 14 alcoholic drinks per week), regular intake of stimulants (e.g. coffee, caffeine supplements or caffeine containing beverages) from midday onwards, suffering from insomnia, nightshift employment or any other such situation that left one unable to have a normal night's sleep, disturbed sleeping patterns caused by external factors (e.g. children, partner, noise), allergic to any of the ingredients in the PEA or placebo formula, pregnant or lactating or any condition or non-medicated supplement use which in the opinion of the investigator made the participant unsuitable for inclusion.

Participants were randomly allocated to either the placebo or PEA group using random allocation software (www.sealedenvelope.com), with both the participants and investigators blinded to allocation.

Participants received either 350 mg of PEA ( 2 x 175 mg Levagen+® capsules) or maltodextrin $(2 \times 175$ mg capsules) taken orally, daily, and with water one hour prior to sleep onset for the study duration (8 weeks). The PEA and placebo product were both housed in opaque capsules and bottles to appear identical. Trial product was supplied by Gencor Pacific (Lantau Island, Hong Kong) and manufactured by Pharmako Biotechnologies (Sydney, Australia).

\section{Intervention}

Upon enrolment, participants completed a health assessment including diet, exercise, medication and medical history, anthropometry measures (weight, height, body mass index, waist/hip circumference), questionnaires [Global Pittsburgh Sleep Quality Index (PSQI), The Sleep Inertia Questionnaire (SIQ), Epworth Sleepiness Scale (ESS), Patient Reported Outcomes Measurement Information System (PROMIS) sleep disturbance, Rand 36-item Health Survey (SF-36) and gastrointestinal tolerance questionnaire] and provided a blood sample (when possible). 
Upon completion of baseline measures, participants were randomised and provided with trial product as well a Consensus Sleep Diary (Carney et al. 2012) and Polar (Kempele, Finland) A370 sleep monitor both of which were completed/worn for 3 consecutive days/nights at baseline, day 5 and weeks 2,4 , and 8 . During the trial, questionnaires were repeated on day 5 and weeks 2 and 4 . Upon completion (week 8), all baseline measures were again recorded.

Table 1

Outcome Measures

\begin{tabular}{|lll}
\hline Outcome measure & Frequency & Tool used \\
\hline Sleep Quality and Quantity & Baseline, day & PSQI, Polar A370 sleep monitor (wrist \\
& 5, weeks 2, 4 \& & actigraphy) and the consensus sleep diary \\
\hline
\end{tabular}

Sleep onset latency
Baseline, day Consensus sleep diary 5 , weeks 2,4 \& 8

Sleep disturbance (waking during the night or waking too early)

Sleep inertia

Daytime sleepiness

Morning grogginess on waking

Daytime nap count and duration

General quality of life

Pathology and Safety markers

Adverse events

PSQI = Global Pittsburgh Sleep Quality Index; PROMIS = Patient Reported Outcomes Measurement Information System; SIQ = The Sleep Inertia Questionnaire; ESS = Epworth Sleepiness Scale; SF-36 = Rand 36-item Health Survey; ALT = Alanintransaminase; AST = Aspartate Transaminase; GGT = Gamma-Glutamyl Transferase; hsCRP = high sensitivity C-reactive Protein; IL = interleukin; TNF = Tumor Necrosis Factor.
Baseline, day Wrist actigraphy, consensus sleep diary and 5, weeks 2,4 \& the PROMIS sleep disturbance questionnaire 8

Baseline, day
5, weeks 2,4 \&

Baseline, day SIQ and consensus sleep diary

5, weeks 2,4 \&

8

Baseline, day 5 , weeks 2,4 \& 8

Baseline, day 5 , weeks 2,4 \& 8

Baseline, day 5 , weeks 2,4 \& 8

Baseline and week 8

Albumin, ALT, AST, GGT, total bilirubin, hsCrp,

Continuously IL10, IL6, IL8 and TNFa
Spontaneously reported by the participant or noticed by a trial supervisor 


\section{Statistical analysis}

A sample size of 100 participants was required, based on the power to detect a change of 2 PSQI points between the placebo and treatment groups using and effect size: 0.67, Alpha error probability: 0.05, Power 0.95 . Based on an approximate $20 \%$ drop-out rate 125 participants were recruited.

Data was analysed with R (Vienna, Austria), using a range of native statistical functions and functions from the packages tidyverse, rcompanion, dplyr, reshape2, and ggplot. Linear regression slope calculation for later analysis was performed in Microsoft Excel. Once assessed for normality, differences between group means were assessed with both Student's t-test and Mann-Whitney U (non-parametric) tests, accordingly. Linear modelling via repeated measures ANOVA was carried out to test further the likelihood of a significant difference between products over the length of the study. Repeated measures ANOVA/ANCOVA were used to analyze within groups variables from all time points, with and without covariates. General linear mixed modelling was also performed on participant data to compare the group dynamics. Results were considered statistically significant if $p<0.05$.

Analysis for sleep onset latency was undertaken only for participants where sleep latency was more than 10 minutes at baseline ( $n=78$ participants).

\section{Results}

Of the 125 randomized participants, 103 completed the study (55 PEA and 48 placebo), 16 were lost to follow up and six dropped out due to adverse events: two in the PEA group (loss of taste and reduced sleep quality) and four in the placebo group (stomach pain, diarrhoea, dizziness, worse sleep).

No significant differences were observed between the two groups for any baseline demographic data. 
Table 2

Baseline demographic results

\begin{tabular}{|lll|}
\hline & PEA & Placebo \\
\hline Male & 25 & 14 \\
\hline Female & 30 & 34 \\
\hline Waist circumference $(\mathrm{cm})$ & $91.6 \pm 14.4$ & $89.4 \pm 14.0$ \\
\hline Hip circumference $(\mathrm{cm})$ & $104.6 \pm 10.4$ & $104.0 \pm 7.9$ \\
\hline Heart rate $(\mathrm{bpm})$ & $63.2 \pm 9.3$ & $62.9 \pm 9.3$ \\
\hline Height $(\mathrm{cm})$ & $171.3 \pm 8.2$ & $170.9 \pm 10.9$ \\
\hline Weight $(\mathrm{kg})$ & $79.4 \pm 17.6$ & $75.7 \pm 17.1$ \\
\hline $\begin{array}{l}\text { N.B. Data is presented as mean } \pm \text { standard deviation; PEA = palmitoylethanolamide: bpm = beats per } \\
\text { minute. }\end{array}$ & \\
\hline
\end{tabular}

Sleep quality was rated as moderate for both groups from the PSQI (Buysse et al. 1989) score with no difference between groups at baseline present. (Table 3). At week 8 , both groups had improved their PSQI scores similarly (Table 3).

Table 3

The Pittsburgh Sleep Quality Index

\begin{tabular}{|lll|}
\hline & PEA & Placebo \\
\hline Baseline & $11.2 \pm 2.8$ & $11.7 \pm 3.3$ \\
\hline Day 5 & $9.0 \pm 2.7$ & $9.8 \pm 3.4$ \\
\hline Week 2 & $8.2 \pm 2.7$ & $8.8 \pm 3.3$ \\
\hline Week 4 & $7.8 \pm 3.0$ & $8.2 \pm 3.4$ \\
\hline Week 8 & $7.6 \pm 3.1$ & $7.7 \pm 3.6$ \\
\hline N.B. Data presented as mean \pm standard deviation; PEA $=$ palmitoylethanolamide. \\
\hline
\end{tabular}

There was no significant difference in sleep quantity or quality for actigraphy measurements or sleep diaries at baseline or 8 weeks between groups (Tables $4 \& 5$ ). There was no significant difference for sleep onset latency (time to fall asleep) at baseline between groups (Table 5). A sub-group analysis utilising general linear mixed model analysis for individuals with sleep onset $>10$ minutes at baseline showed a significant reduction in sleep onset latency time (total and change) for weeks 4 and 8 in the PEA group compared with the placebo group (Table 4; Fig. 1 ; $p<0.05$ ). 
Table 4

Sleep actigraphy data

\begin{tabular}{|c|c|c|c|c|c|c|}
\hline & PEA & & & Placebo & & \\
\hline & Baseline & Week 4 & Week 8 & Baseline & Week 4 & Week 8 \\
\hline $\begin{array}{l}\text { Total Sleep time } \\
\text { (hrs) }\end{array}$ & $7.49 \pm 1.1$ & $7.66 \pm 1.2$ & $7.58 \pm 1.1$ & $7.52 \pm 1.2$ & $7.54 \pm 1.2$ & $7.48 \pm 1.1$ \\
\hline Sleep Time (hrs) & $7.00 \pm 1.0$ & $7.10 \pm 1.0$ & $7.03 \pm 1.1$ & $6.98 \pm 1.2$ & $7.02 \pm 1.2$ & $6.97 \pm 1.1$ \\
\hline Interruptions (min) & $\begin{array}{l}34.3 \pm \\
14.1\end{array}$ & $\begin{array}{l}32.3 \pm \\
11.6\end{array}$ & $\begin{array}{l}32.2 \pm \\
11.2\end{array}$ & $\begin{array}{l}32.1 \pm \\
12.2\end{array}$ & $\begin{array}{l}31.3 \pm \\
12.4\end{array}$ & $\begin{array}{l}30.9 \pm \\
11.8\end{array}$ \\
\hline Sleep quality $(1-5)$ & $2.7 \pm 0.6$ & $3.1 \pm 0.7$ & $3.1 \pm 0.7$ & $2.5 \pm 0.7$ & $3.0 \pm 0.7$ & $2.9 \pm 0.9$ \\
\hline $\begin{array}{l}\text { Sleep Continuity (1- } \\
5)\end{array}$ & $3.2 \pm 0.9$ & $3.2 \pm 0.9$ & $3.2 \pm 0.9$ & $3.2 \pm 0.9$ & $3.4 \pm 1.0$ & $3.3 \pm 0.9$ \\
\hline $\begin{array}{l}\text { Sleep Percentage } \\
(\%)\end{array}$ & $92.4 \pm 3.9$ & $92.9 \pm 3.0$ & $92.8 \pm 2.4$ & $92.8 \pm 3.0$ & $91.1 \pm 7.5$ & $93.0 \pm 2.9$ \\
\hline
\end{tabular}

Table 5

Sleep diary data

\begin{tabular}{|c|c|c|c|c|c|c|}
\hline & PEA & & & Placebo & & \\
\hline & Baseline & Week 4 & Week 8 & Baseline & Week 4 & Week 8 \\
\hline Sleep time (hrs) & $6.1 \pm 1.5$ & $6.7 \pm 1.4$ & $6.7 \pm 1.3$ & $6.1 \pm 1.5$ & $6.5 \pm 1.3$ & $6.5 \pm 1.5$ \\
\hline $\begin{array}{l}\text { Sleep Latency }{ }^{\mathrm{a}} \\
(\mathrm{min})\end{array}$ & $\begin{array}{l}42.8 \pm \\
42.2\end{array}$ & $\begin{array}{l}26.8 \pm \\
26.3^{*}\end{array}$ & $\begin{array}{l}23.4 \pm \\
23.1^{*}\end{array}$ & $\begin{array}{l}36.2 \pm \\
40.5\end{array}$ & $\begin{array}{l}34.2 \pm \\
40.5\end{array}$ & $\begin{array}{l}30.3 \pm \\
39.2\end{array}$ \\
\hline Interruptions (n) & $3.3 \pm 2.1$ & $3.0 \pm 2.3$ & $3.3 \pm 3.0$ & $3.9 \pm 3.8$ & $3.0 \pm 3.0$ & $2.9 \pm 2.8$ \\
\hline Interruptions (min) & $\begin{array}{l}41.0 \pm \\
39.3\end{array}$ & $\begin{array}{l}29.9 \pm \\
30.1\end{array}$ & $\begin{array}{l}35.0 \pm \\
34.8\end{array}$ & $\begin{array}{l}35.3 \pm \\
32.0\end{array}$ & $\begin{array}{l}31.6 \pm \\
41.5\end{array}$ & $\begin{array}{l}32.6 \pm \\
42.7\end{array}$ \\
\hline
\end{tabular}

There was no change in sleep disturbance or sleep interruptions as measured by consensus sleep diary, actigraphy or the PROMIS questionnaire during the study (Tables 4-6). There were no differences in daytime sleepiness levels (ESS) for both groups throughout the study (Table 6). 
There was a significant difference $(p<0.05)$ in change from baseline for time to feel completely awake (sleep inertia) and domain scores for cognition in the PEA group compared to the placebo at week 8 . No other domains were significantly different between groups (Table 6).

Table 6

Data from sleep questionnaires including domain scores

\begin{tabular}{|c|c|c|c|c|c|c|}
\hline & \multicolumn{3}{|c|}{ PEA } & \multicolumn{3}{|c|}{ Placebo } \\
\hline & Baseline & Week 4 & Week 8 & Baseline & Week 4 & Week 8 \\
\hline Epworth Sleepiness Scale & $6.5 \pm 4.4$ & $4.6 \pm 3.8$ & $4.7 \pm 4.1$ & $6.7 \pm 4.1$ & $4.8 \pm 3.9$ & $4.3 \pm 4.1$ \\
\hline PROMIS & $\begin{array}{l}61.5 \pm \\
6.0\end{array}$ & $\begin{array}{l}56.8 \pm \\
6.5\end{array}$ & $\begin{array}{l}55.3 \pm \\
6.6\end{array}$ & $\begin{array}{l}62.2 \pm \\
6.5\end{array}$ & $\begin{array}{l}56.5 \pm \\
6.7\end{array}$ & $\begin{array}{l}55.1 \pm \\
9.0\end{array}$ \\
\hline SIQ Total score & $\begin{array}{l}45.1 \pm \\
15.7\end{array}$ & $\begin{array}{l}36.9 \pm \\
13.1\end{array}$ & $\begin{array}{l}37.1 \pm \\
12.4\end{array}$ & $\begin{array}{l}45.0 \pm \\
12.4\end{array}$ & $\begin{array}{l}37.1 \pm \\
15.0\end{array}$ & $\begin{array}{l}36.8 \pm \\
15.1\end{array}$ \\
\hline SIQ Physiological & $\begin{array}{l}15.8 \pm \\
6.0\end{array}$ & $\begin{array}{l}12.2 \pm \\
4.5\end{array}$ & $\begin{array}{l}12.4 \pm \\
4.7\end{array}$ & $\begin{array}{l}16.2 \pm \\
4.9\end{array}$ & $\begin{array}{l}12.8 \pm \\
5.7\end{array}$ & $\begin{array}{l}12.6 \pm \\
5.5\end{array}$ \\
\hline $\begin{array}{l}\text { SIQ Responses to Sleep } \\
\text { Inertia }\end{array}$ & $\begin{array}{l}13.8 \pm \\
5.2\end{array}$ & $\begin{array}{l}12.3 \pm \\
4.9\end{array}$ & $\begin{array}{l}11.6 \pm \\
4.3\end{array}$ & $\begin{array}{l}14.5 \pm \\
4.6\end{array}$ & $\begin{array}{l}12.0 \pm \\
4.7\end{array}$ & $\begin{array}{l}12.0 \pm \\
5.0\end{array}$ \\
\hline SIQ Cognitive & $\begin{array}{l}10.5 \pm \\
4.6\end{array}$ & $9.0 \pm 3.7$ & $8.0 \pm 3.2^{\star}$ & $9.4 \pm 3.0$ & $7.4 \pm 3.6$ & $7.8 \pm 4.1$ \\
\hline SIQ Emotional & $4.9 \pm 2.6$ & $4.4 \pm 2.3$ & $4.2 \pm 1.6$ & $4.9 \pm 2.3$ & $4.5 \pm 2.7$ & $4.8 \pm 2.8$ \\
\hline $\begin{array}{l}\text { SIQ Time to feel completely } \\
\text { awake }\end{array}$ & $\begin{array}{l}25.9 \pm \\
25.3\end{array}$ & $\begin{array}{l}18.4 \pm \\
21.1\end{array}$ & $\begin{array}{l}14.7 \pm \\
17.5^{\star}\end{array}$ & $\begin{array}{l}23.6 \pm \\
23.8\end{array}$ & $\begin{array}{l}20.4 \pm \\
20.4\end{array}$ & $\begin{array}{l}22.4 \pm \\
25.1\end{array}$ \\
\hline
\end{tabular}

No significant differences either within or between groups were found for any pathology marker or for the SF-36. All pathology markers were within normal ranges throughout the study. There was no difference between the placebo and PEA group for compliance $(9.7 \pm 8.4$ and $13.2 \pm 9.9$ capsules remaining respectively) or reported gastrointestinal tolerance issues between groups (4 reported cases in the placebo group).

\section{Discussion}

The aim of this study was to evaluate the efficacy of PEA supplementation on sleep quality and quantity in healthy adults with sleep pattern disturbance. It was hypothesised that PEA supplementation one hour prior to sleep onset would improve sleep quality, quantity and onset time. No treatment effect was seen for the total PSQI score or sleep duration, despite both groups reporting poor sleep at baseline as 
measured by the PSQI. This is due to both groups reporting a reduction in PSQI scores from baseline scores.

The reduction in PSQI in both groups could be due to a number of possible reasons. One reason may be a placebo effect. A second possibility is that participants may have become more focussed on measuring individual aspects their sleep. As such, baseline scores may be inflated, with participants not having an accurate reflection of their sleep behaviour. However, after 8-weeks in the study, participants may have had an improved recall on the facets of their sleep such that the PSQI total score may have increased in accuracy.

To accurately measure sleep duration, two methods of sleep measurement were incorporated in the study. Sleep duration was measured by both consensus sleep diary and wrist actigraphy which were consistent between measures but overall, slightly lower, though not significant, in consensus diary reporting (0.3-0.8 hours). Previous research has demonstrated a moderate correlation between diary and actigraphy measures, with discrepancies higher in groups who have less sleep (Carney et al. 20120; Hanish et al. 2017). In our study, both groups reported achieving approximately 6-7 hours of sleep per night. Therefore, it is likely that this study population suffered more from sleep disturbance and high sleep onset latency rather than lack of sleep duration.

A key finding of this study indicated that PEA significantly reduced the amount of time to fall asleep in individuals with sleep latency issues. This reduction in sleep onset latency could be the result of a number of physiological responses to PEA. An increase in AEA levels via the endocannabinoid system (Vaughn et al. 2010; Ho et al. 2008), a change in inflammatory signalling or reduction in pain sensitivity could all promote faster sleep (Betoni et al. 2013; Di Cesare et al. 2013; Helyes et al. 2003; Costa et al. 2008; LoVerme et al. 2006; Luongo et al. 2013). Sleep disturbance has been linked with inflammation and inflammatory signalling that contributes to possible sleep disturbance (Irwin et al. 2015; Mullington et al. 2010; Irwin et al. 2016). Therefore, a change in inflammation sensitivity (signalling or receptor activity) could alter sleep patterns. However, as this trial did not measure AEA concentrations, or find any change in serum cytokines, this is speculative.

PEA supplementation improved the time to feel fully awake and cognition on waking. This is of particular interest as sleep inertia and daytime grogginess is a common side effect of many pharmaceutical options for the treatment of sleep disturbance (Miner et al. 2017). The combination of the PEA group reporting falling asleep faster and waking up feeling more alert and awake compared to the placebo group, suggests that future studies on PEA and sleep should focus on populations with difficulty getting to sleep and/or waking up.

A major limitation of this study was that it was disrupted by the COVID-19 pandemic, limiting the number of participants able to provide blood samples. Therefore, we were only able to measure pathology markers on a limited number of participants greatly reducing the power of the analysis making it difficult to make inferences on the outcomes. Had all participants been able to provide a blood sample, it may have provided stronger evidence for changes in blood cytokines and supported an anti-inflammatory 
mechanism. A proposed area of focus for future studies on PEA and sleep would benefit by having a studied powered for biochemistry markers such as AEA and inflammatory cytokines.

\section{Conclusion}

Overall, the results of this study support PEA as a potential sleeping aid capable of reducing sleep onset time in individuals with sleep latency issues and improving cognition on waking. Further studies would benefit by specifically focusing on sleep latency and/or including participants with severely disturbed sleep.

\section{Abbreviations}

Palmitoylethanolamide (PEA); anandamide (AEA); non-rapid eye movement (NREM); transient receptor potential cation channel subfamily V member 1 (TrpV1); cold-water dispersible (CWD); Global Pittsburgh Sleep Quality Index (PSQI); The Sleep Inertia Questionnaire (SIQ); Epworth Sleepiness Scale (ESS); Patient Reported Outcomes Measurement Information System (PROMIS); Rand 36-item Health Survey (SF-36); Alanintransaminase (ALT); Aspartate Transaminase (AST); Gamma-Glutamyl Transferase (GGT); high sensitivity C-reactive Protein (hsCRP); Interleukin (IL); Tumor Necrosis Factor (TNF); beats per minute (BPM).

\section{Declarations}

\section{Ethics approval and consent to participate}

This study was approved by the Bellberry Ltd Human research and ethics committee (approval number HREC2018-08-668-A-1) and carried out in accordance with current International Conference on Harmonization Guideline for Good Clinical Practice. All participants provided written informed consent prior to enrolment into the trial.

\section{Consent for publication}

Not applicable

\section{Availability of data and materials}

The datasets generated and/or analysed during the current study are not publicly available due to commercial agreements, but are available from the corresponding author on reasonable request.

\section{Competing interests}

The authors declare that they have no competing interests

\section{Funding}


This study was funded by Gencor Pacific Ltd, Hong Kong. The trial sponsors had no involvement in the design of the study and collection, analysis, and interpretation of data or in writing the manuscript.

\section{Authors' contributions}

Conceptualization, A.R. and D.B.; methodology, A.R., A.M. and D.B.; formal analysis, A.M. and A.R.; investigation, P.E. and A.M.; resources, A.R. and D.B.; data curation, A.M. and A.R; writing-original draft preparation, P.E. and D.B.; writing-review and editing, A.R, A.M. and D.B.; visualization, A.R. and D.B.; supervision, A.R. and D.B.; project administration, A.R. and D.B.; funding acquisition, D.B. All authors have read and agreed to the published version of the manuscript.

\section{Acknowledgements}

Not applicable

\section{References}

1. Chattu VK, Manzar MD, Kumary S, et al. The global problem of insufficient sleep and its serious public health implications. Healthcare (Basel). 109;7: 1

2. Medic G, Wille M, Hemels M. Short- and long-term health consequences of sleep disruption. Nat Sci Sleep. 2017;9:151-161

3. The extraordinary importance of sleep; The detrimental effects of inadequate sleep on health and public safety drive and explosion of sleep research. PT. 2018;43:758-763

4. Kesner AJ, Lovinger DM. Cannabinoids, endocannabinoids and sleep. Front Mol Neurosci. 2020;13:125

5. Walker MP, Brakefield T, Seidman J, et al. Sleep and time course of motor skill learning. Learn Mem. 2003;10:275-284

6. Irwin MR, Witarama T, Caudill M, et al. Sleep loss activates cellular inflammation and signal transducer and activator of transcription (STAT) family proteins in humans. Brain Behav Immun 2015;47:86-92.

7. Krueger JM. The role of cytokines in sleep regulation. Curr Pharm Des 2008;14:3408-16.

8. Mullington JM, Simpson NS, Meier-Ewert HK, et al. Sleep loss and inflammation. Best Pract Res Clin Endocrinol Metab 2010;24:775-84.

9. Irwin MR, Olmstead R, Carroll JE. Sleep Disturbance, Sleep Duration, and Inflammation: A Systematic Review and Meta-Analysis of Cohort Studies and Experimental Sleep Deprivation. Biol Psychiatry 2016;80:40-52.

10. Vaughn LK, Denning G, Stuhr KL, et al. Endocannabinoid signalling: has it got rhythm? Br J Pharmacol 2010;160:530-43

11. Ho WS, Barrett DA, Randall MD. 'Entourage' effects of N-palmitoylethanolamide and Noleoylethanolamide on vasorelaxation to anandamide occur through TRPV1 receptors. $\mathrm{Br} J$ 
Pharmacol 2008;155:837-46.

12. Prospero-Garcia O, Amancio-Belmont O, Becerril Melendez AL, et al. Endocannabinoids and sleep. Neurosci Biobehav Rev 2016;71:671-679.

13. Murillo-Rodriguez E, Poot-Ake A, Carrion-Arias 0 , et al. The emerging role of the endocannabinoid system in the sleep-wake cycle modulation. Cen Nerv Syst Agents Med Chem. 2011;1:189-196

14. O'Sullivan SE, Kendall DA. Cannabinoid activation of peroxisome proliferator-activated receptors: potential for modulation of inflammatory disease. Immunobiology. 2010;215:611-616

15. Alhouayek M, Muccioli G. Harnessing the anti-inflammatory potential of palmitoylethanolamide. Drug Discov 2014;19:1632-1639

16. Gabrielsson L, Mattsson S, Fowler C.Palmitoylethanolamide for the treatment of pain: pharmacokinetics, safety and efficacy. Br J Clin Pharmacol 2016;82:932-942.

17. Keppel Hesselink J, de Boer T, Witkamp R. Palmitoylethanolamide: A natural body-own antiinflammatory agent, effective and safe against influenza and common c International Journal of Inflammation 2013;2013:1-8.

18. Ambrosino P, Soldovieri MV, Russo C, et al. Activation and desensitization of TRPV1 channels in sensory neurons by the PPARalpha agonist palmitoylethanolamide. Br J Pharmacol 2013;168:143044.

19. Franco-Cereceda A, Rudehill A. Capsaicin-induced vasodilataion of human coronary arteries in vitro is mediated by calcitonin gene-related peptide rather than substance $P$ or neurokinin A. Acta Physiol Scand 1989;136:575-80.

20. Zygmunt PM, Petersson J, Andersson DA, et al. Vanilloid receptors on sensory nerves mediate the vasodilator acion of anandamide. Nature 1999;400:452-7.

21. Evangelista M, Cilli, De Vitis R, et al. Ultra-micronized Palmitoylethanolamide Effects on Sleep-wake Rhythm and Neuropathic Pain Phenotypes in Patients with Carpal Tunnel Syndrome: An Open-label, Randomized Controlled Study. CNS Neurol Disord Drug Targets 2018;17:291-298.

22. Canteri L, Petrosino S, Guida G. Reduction in the consumption of anti inflammatory and analgesic agents during the treatment of chronic neuropathic pain in patients with compression lumbosciatalgia and treatment with NORMAST ® 300mg . DOLOR 2010;25:227-234

23. Chirchiglia D, Cione E, Caroleo MC, Wang M, Di Mizio G, Faedda N, Giacolini T, Siviglia S, Guidetti V, Gallelli L. Effects of add-on ultramicronized n-palmitol ethanol amide in patients suffering of migraine with aura: a pilot s Front Neruol 2018;9:674

24. Conigliaro R, Drago V, Foster PS, Schievano C, Di Marzo V. Use of palmitoylethanolamide in the entrapment neuropathy of the median in the wrist.Minerva med 2011;102:141-147.

25. Dalla Volta G, Zavarize P, Ngonga GK, Carli D. Ultramicronized palmitoylethanolamide reduces frequency and pain intensity in $\mathrm{m}$ A pilot study. Int J Neurol Brain Dis 2016;3:1-5

26. Keppel Hesselink J, Hekker TAM. Therapeutic utility of palmitoylethanolamide in the treatment of neuropathic pain associated with various pathological conditions: a case series. J Pain Res 
2012;5:437-442

27. Marini I, Bartolucci ML, Bortolotti F, Gatto MR, Bonetti GA. Palmitoylethanolamide versus a nonsteroidal anti-inflammatory drug in the treatment of temporomandibular joint inflammatory pain. J Orofac Pain 2012;26:99-104

28. Briskey D, Mallard AR, Rao A. Increased absorption of palmitoylethanolamide using a novel dispersion system (LipiSperse ${ }^{\circledR}$ ). J Nutraceuticals Food Sci. 2020;5

29. Buysse DJ, Reynolds CF 3rd, Monk TH, Berman SR, Kupfer DJ. The Pittsburgh Sleep Quality Index: a new instrument for psychiatric practice and research. Psychiatry Res. 1989 May;28(2):193-213.

30. Betoni I, Comelli F, Colombo A, et al. Non-neuronal cell modulaion relieves neuropathic pain: eicacy of the endogenous lipid palmitoylethanolamide. CNS Neurol Disord Drug Targets 2013;12:34-44.

31. Di Cesare Mannelli L, D'Agosino G, Pacini A, et al. Palmitoylethanolamide is a disease-modifying agent in peripheral neuropathy: pain relief and neuroprotecion share a PPAR-alpha-mediated mechanism. Mediators Infamm 2013;2013:328797.

32. Helyes $Z$, Nemeth $J$, Than $M$, et al. Inhibitory effect of anandamide on resiniferatoxin induced sensory neuropeptide release in vivo and neuropathic hyperalgesia in the rat. Life Sci 2003;73:234553.

33. Costa B, Comelli F, Betoni I, et al. The endogenous fatty acid amide, palmitoylethanolamide, has antiallodynic and ani-hyperalgesic effects in a murine model of neuropathic pain: involvement of $\mathrm{CB}(1)$, TRPV1 and PPARgamma receptors and neurotrophic factors. Pain 2008;139:541-50.

34. LoVerme J, Russo R, La Rana G, et al. Rapid broad-spectrum analgesia through acivaion of peroxisome proliferator-acivated receptor-alpha. J Pharmacol Exp Ther 2006;319:1051-61.

35. Luongo L, Guida F, Boccella S, et al. Palmitoylethanolamide reduces formalin-induced neuropathiclike behaviour through spinal glial/microglial phenotypical changes in mice. CNS Neurol Disord Drug Targets 2013;12:45-54.

36. Luongo L, Guida F, Boccella S, et al. Palmitoylethanolamide reduces formalin-induced neuropathiclike behaviour through spinal glial/microglial phenotypical changes in mice. CNS Neurol Disord Drug Targets 2013;12:45-54.

37. Miner B, Kryger MH, Sleep in the Aging Population. Sleep Med Clin. 2017;12:31-38

38. Carney CE, Buysee DJ, Ancoli-Israel S, et al. The Consensus Sleep Diary: standardizing prospective sleep self-monitoring. Sleep. 2012;35:287-302

39. Hanish AE, Lin-Dyken DC, Han JC. PROMIS sleep disturbance and sleep-related impairment in adolescents: examining psychometrics using self-seport and actigraphy. Nurs Res. 2017;66:246-251

\section{Figures}




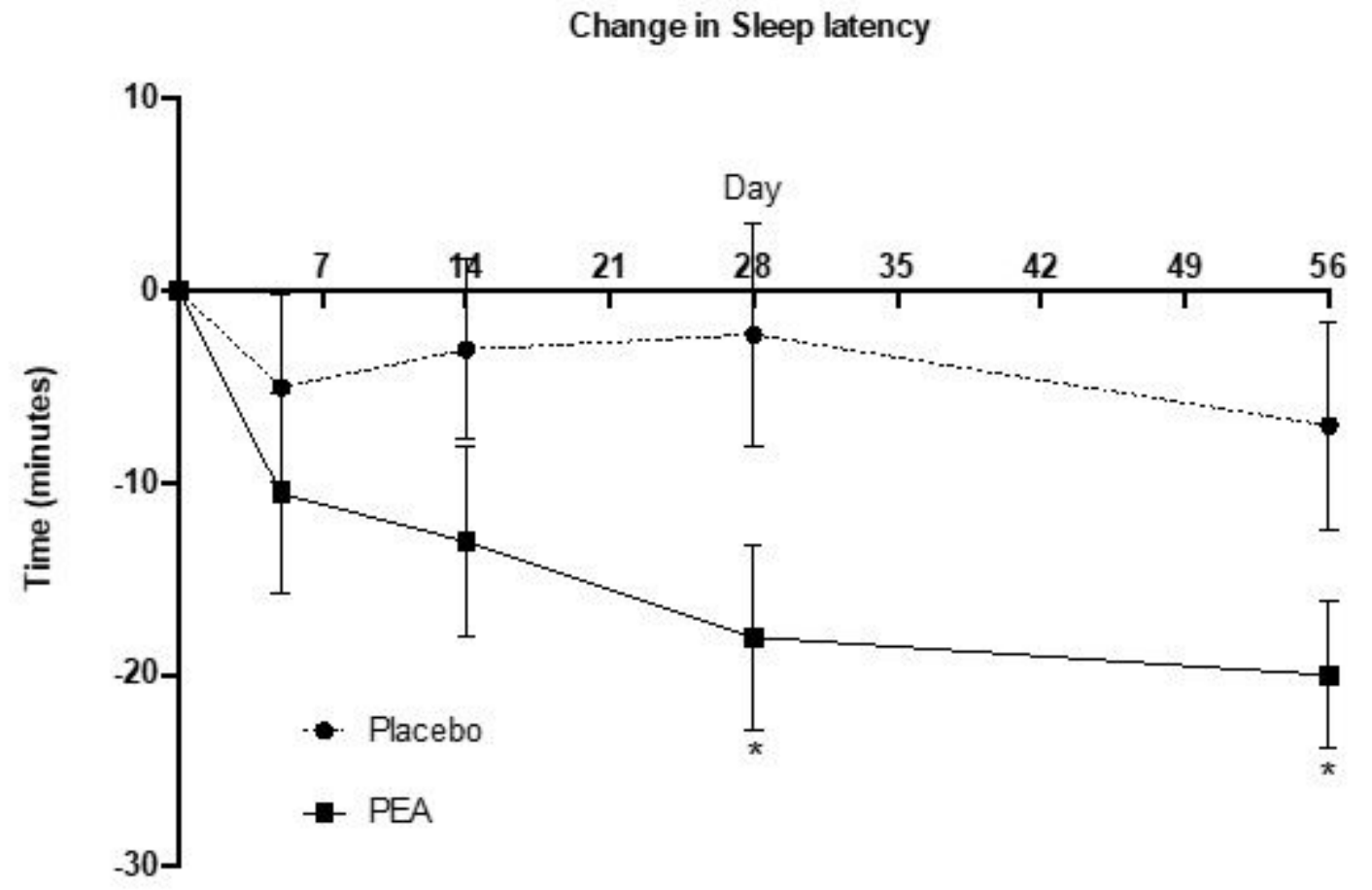

\section{Figure 1}

Change in Sleep onset latency (time to get to sleep) over 8 weeks for participants reporting time to sleep $>10$ minutes at baseline. 